\title{
Intelligent Self-learning System of AMT Gear Position
}

\author{
Yulong Lei, Xiaoxin Gang, Yao Fu* and Jianlong $\mathrm{Hu}$ \\ State Key Laboratory of Automotive Simulation and Control, Jilin University, Changchun, China \\ ${ }^{*}$ Corresponding author
}

\begin{abstract}
This essay makes an analysis of shift principle and the location distribution of the gear of the AMT system without shift actuator. According to the self-study theory, we exploit an intelligent gear position self-study system and try to figure out the problems of finding the certain gear position because of the factors like assembly error, process error and abrasion. The innovative point is that it can improve the accuracy and robustness of the electric shift actuator and the success rate of shifting and achieve the fast and accurate control of shifting of the AMT system.
\end{abstract}

Keywords-AMT; intelligent self-learning system; gear position

\section{INTRODUCTION}

Based on the fuzzy self-adaptive and double-loop PID control can realize the rapid and accurate shifting control. But we must make sure that the target input of the controller of PID is highly accurate. That is to say we must make sure each gear with accurate position in the AMT system, and then we can have the accurate control of the shift actuator. Otherwise we will decline the accuracy of the control system and have the problems of shifting process. However during the actual control and application process .The position of each gear in each transmission is different because of the inaccuracy during processing and fixing. And mechanical wear by long term usage cause the differences of each gear in the transmission. This contributes great difficulty to the accusation of the position of each gear in the AMT system. And it also can influent the control accuracy of the shift actuator and the shifting quality of the AMT system.

Li Yong and his group study the strategy of control in the AMT shift actuator system [1]. And then amend the position of each gear online and off-line. Zhao and his study the strategy of control of the commercial vehicle with hybrid power [2]. And optimize the study order of each gear and the gear engaging study strategy. The above study is available to the AMT system including the shift actuator. However it is useless for electric cars without shift actuator of the AMT system position study and exploit. Therefore, this paper focuses on the research in this area.

\section{ANALYSIS OF THE GEAR POSITION OF THE AMT SYSTEM}

As shown in Figure I (a), the AMT system we study in this essay cancels the shift construction. And the interlocking mechanism in the transmission can make sure that when a shift fork is on the gear, another one is in the position of neutral gear.
And when both of them are in the same position of neutral gear, the transmission is neutral gear.
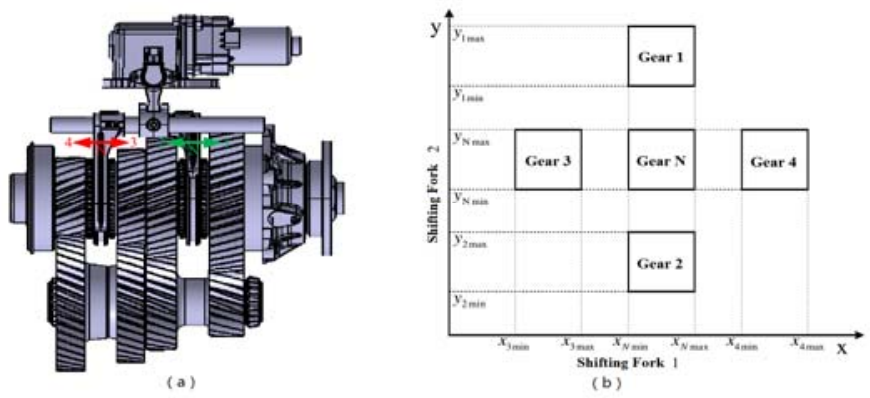

FIGURE I. THE ACTUAL OBJECT AND DEFINITION CHART OF AMT GEAR POSITION

According to the principle of the structure of AMT system, we can build a gear position for AMT system's coordinate system by using position of shit fork 1 as abscissa and position of shift fork 2 as ordinate. As shown in Figure I. (b).

Defining the position interval of Gear 1 on the y-axis is $\left(\mathrm{y}_{1 \min }, \mathrm{y}_{1 \max }\right)$, the position interval of Gear 2 on the $\mathrm{y}$-axis is $\left(\mathrm{y}_{2 \min }, \mathrm{y}_{2 \max }\right)$, the position interval of Gear 3 on the $\mathrm{x}$-axis is $\left(\mathrm{x}_{3 \min } \cdot \mathrm{x}_{3 \max }\right)$, the position interval of Gear 4 on the $\mathrm{x}$-axis is $\left(\mathrm{x}_{4 \min }, \mathrm{x}_{4 \max }\right)$, the position interval of Gear $\mathrm{N}$ on the $\mathrm{x}$-axis and $\mathrm{y}$-axis is $\left(\mathrm{x}_{\mathrm{N} \text { min }}, \mathrm{x}_{\mathrm{N} \text { max }}\right)$, $\left(\mathrm{y}_{\mathrm{N} \text { min }}, \mathrm{Y}_{\mathrm{N} \text { max }}\right)$.If taking midpoint of the position interval of each gear as target position of the gear, such as $\mathrm{x}_{\mathrm{N}}=0.5\left(\mathrm{x}_{\mathrm{Nmin}}+\mathrm{x}_{\mathrm{Nmax}}\right)$, then we can get each AMT gear's position in the $\mathrm{x}-\mathrm{y}$ coordinate system , as shown in Table I.

TABLE I. POSITION OF EACH ATM GEAR IN THE X-Y COORDINATE SYSTEM

\begin{tabular}{lcc}
\hline Gear & Axis x & Axis y \\
\hline Gear N & $0.5\left(x_{\mathrm{N} \min }+x_{\mathrm{N} \max }\right)$ & $0.5\left(y_{\mathrm{N} \min }+y_{\mathrm{N} \max }\right)$ \\
Gear 1 & $0.5\left(x_{\mathrm{N} \min }+x_{\mathrm{N} \max }\right)$ & $0.5\left(y_{1 \min }+y_{1 \max }\right)$ \\
Gear 2 & $0.5\left(x_{\mathrm{N} \min }+x_{\mathrm{N} \max }\right)$ & $0.5\left(y_{2 \min }+y_{2 \max }\right)$ \\
Gear 3 & $0.5\left(x_{3 \min }+x_{3 \max }\right)$ & $0.5\left(y_{\mathrm{N} \min }+y_{\mathrm{N} \max }\right)$ \\
Gear 4 & $0.5\left(x_{4 \min }+x_{4 \max }\right)$ & $0.5\left(y_{\mathrm{N} \min }+y_{\mathrm{N} \max }\right)$ \\
\hline
\end{tabular}

The Table I show that each AMT gear is corresponding to the different positions of the two shift fork. Therefore, only if determine the position of the two shift fork at the same time, we can accurate judgment in which gear AMT system and accurate position of each gear. In this paper, the precise position of each gear is self-learning based on gear position 
coordinate system, to ensure the accuracy of the shit actuator control system and success rate of the shift.

\section{GEAR POSITION OfFLINE SELF-LEARNING}

Offline self-learning is making each gear of AMT system self-learning in the offline state to determine the position of each point in Table I. This self-learning method is mainly suitable for AMT system's offline detection and maintenance services. When an AMT product is assembled, the first, it must be calibrated to the position of each gear. In the past, most of people take the method of manual calibration. In order to improve the calibration efficiency and accuracy, in this paper, we design a gear position offline learning strategy, so as to take the automatic calibration.

Because of the AMT system must be through neutral gear in the process of switching any gears, we must ensure the accuracy of neutral gear position. If neutral gear position inaccurate or not return to accurate neutral gear position in shifting, may be lead to the following two kinds of situations can't be shifted.(1)Although the actual gear is neutral, because of imprecision of the control position, the shift program may think transmission didn't hang into neutral gear and next shift operation is prohibited.(2)Even if the program allows the next operation, if not return to the precise position of neutral gear, when different shift forks that response for different gears is exchanging such as form gear 2 to gear 3,lock mechanism within the transmission play the role of mechanical interlocking to prevent the transmission into the target gear. So it is very important that determine the precise position of AMT system neutral gear.

In the actual offline learning process, internal gear, gear sets, as well as the shifting actuator are just off the assembly line without running-in, so there are large mechanical and frictional resistance, and the shifting is not smooth, which has a great influence on the moving step at the time of neutral selflearning. In order to improve the efficiency and accuracy of self-learning, this paper calibrates the position of each gear according to the order of 1-2-3-4-N. Figure II. shows a block diagram for the offline self-learning.

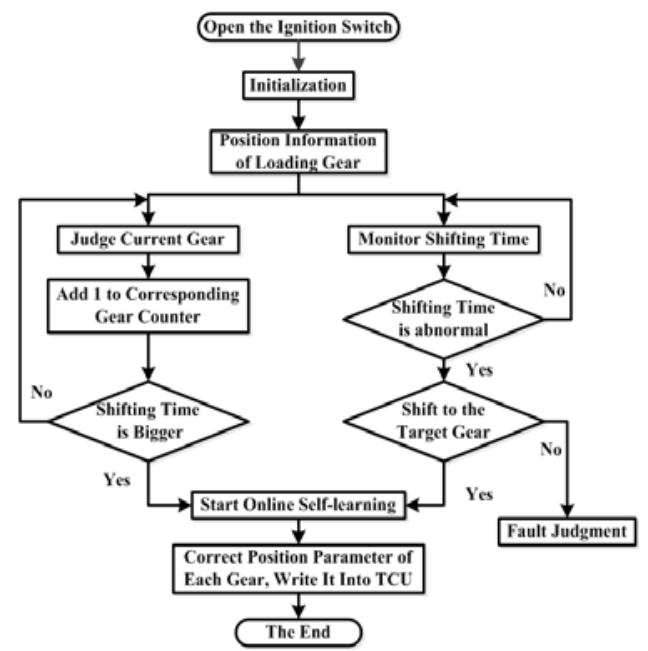

FIGURE II. OFFLINE SELF-LEARNING STRATEGY DIAGRAM OF AMT GEAR POSITION
Initialize after TCU has the electricity, and then start off the offline self-learning functions. Procedures make shifting operations for AMT system according to the order of 1-2-3-4-N, and each gear is shifted three times, and records the position of the gear at each time. In order to ensure the accuracy of the each gear position, the program judges according to each gear position data by self-learning for the three times. If it is accurate, calculate the average value of three times and write it into TCU; if it is not accurate, learn each gear position again, until get the exact gear position. Write each gear position into TCU, then AMT system will be set to neutral gear, and off-line self-learning gets to the end.

\section{ONLINE SELF-LEARNING OF GEAR POSITION}

Online self-learning is also known as the dynamic selflearning, that is to monitor and correct gear position of the AMT system in the vehicle running process, which ensures the accuracy and improves the robustness and successful shifting rate of the control system. The online self-learning strategy designed in this paper includes two functions. The first function is that when the AMT system is running for a period of time, the internal gear, engagement sleeve, shifting forks and gear shifting actuator will have different degrees of wear, and each gear position may change. If continue to use the original parameters for the shifting control, it may get some difficulty or even can't shift. At this point, the wearing degree of the AMT system can be judged based on the using time of each gear. When the using times of a gear is bigger than the setting value, start self-learning of the gear position. For example:

\section{If (Using time of Gear 1T1 > Setting value test)}

Then (Call self-learning and update parameters of each gear position in TCU)

The second function is to monitor the shift of the AMT system on line. When the shifting time is changed to a long time, because of the redundancy between input / output ratio and gear position, the AMT system can be judged whether it is in the target gear of not by calculating the ratio value. When AMT has been judged to be in the target gear, but the actual gear position is not in the setting scope of the program, it indicates that the parameters of gear position have changed, and the parameters should be self-learned again to ensure its accuracy. Figure III shows the block diagram of self-learning for the AMT gear position.

1) After switch on the ignition, initialize the program, and load the information of gear position stored in the EEPROM of TCU, then get to normal operation of the vehicle.

2) Set the shifting frequency counters of each AMT gear. In the process of vehicle running, the shifting counters of the corresponding gear plus 1 at each shifting operation. When the value of the counter is greater than the set value, it enters the online self-learning module, and re-measures each gear position, in order to avoid problems of binding and failing shift resulted from gear position changes caused by wear; If it does not meet the conditions of online self-learning, continue the judging process. Test, setting time of gear shifting can determined through the simulating calculation and experiment. 
3) During the process of vehicle running, monitor whether of each gear shifting time is abnormal at real-time: if the shifting time is normal, continue to monitor; If the shifting time is abnormal and greater than the normal time, judge whether it is in the target gear according to the speed ratio of output to input: if it is in the target gear, it shows that the gear position has changed, then start online self-learning function, to learn the gear position; If not, determine whether there is a breakdown, and take corresponding measures.

4) Online self-learning methods of gear position are basically as same as that of offline learning, no longer described in detail in this paper.

Get the precise position of each gear through online selflearning, then update the target position of each gear stored in TCU, and online self- learning process get to the end.

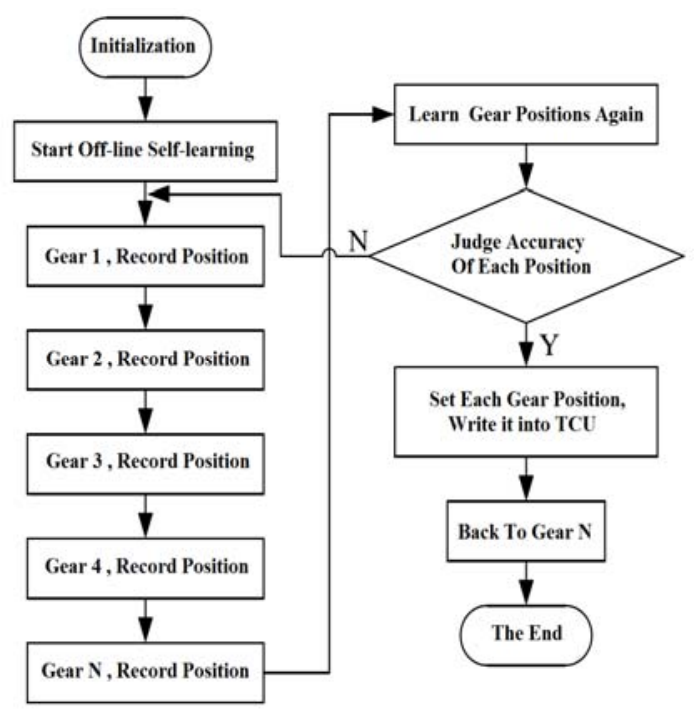

FIGURE III. ONLINE SELF-LEARNING STRATEGY DIAGRAM OF AMT GEAR POSITION

\section{EXPERIMENTAL VERIFICATION}

In order to verify the effectiveness and accuracy of the developed self-learning system of gear position, this paper respectively had an offline self-learning test on AMT system just rolled off the production line and an online self-learning test on the pure electric bus equipped with the AMT.

\section{A. Results and Analysis of Offline Self-learning Test}

Figure IV shows results of offline self-learning test for each gear position of the AMT system just rolled off the production line, including the offline self-learning state and the position curve of shifting fork 1,2 . After the program initialization, offline self-learning status changes from 0 to 1 , and start to measure the actual position of each gear. In the process of offline self-learning, TCU controls shifting actuator to shift continuously for three cycles in the order of 1-2-3-4-N, after self-learning the state changed to 2 . Table II shows results of three measurements for the actual position of each gear in the process of offline self-learning.

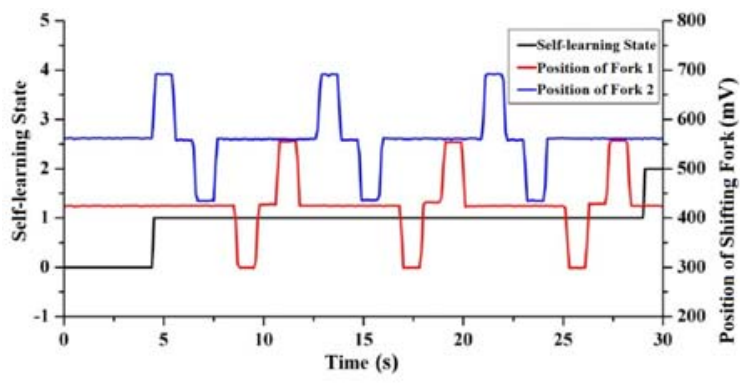

FIGURE IV. OFFLINE SELF-LEARNING CURVE OF AMT GEAR POSITION

TABLE II. MEASUREMENT RESULTS OF ACTUAL POSITION OF EACH AMT GEAR

\begin{tabular}{|c|c|c|c|c|c|}
\hline Shifting Fork & 1 & 2 & 3 & 4 & $\mathrm{~N}$ \\
\hline \multirow{3}{*}{$\begin{array}{l}\text { Position of } \\
\text { Shifting Fork } 1 \\
(\mathrm{mV})\end{array}$} & 425 & 424 & 299 & 556 & 426 \\
\hline & 423 & 425 & 301 & 553 & 430 \\
\hline & 428 & 422 & 296 & 554 & 427 \\
\hline \multirow{3}{*}{$\begin{array}{l}\text { Position of } \\
\text { Shifting Fork } 2 \\
(\mathrm{mV})\end{array}$} & 692 & 435 & 560 & 561 & 560 \\
\hline & 689 & 431 & 562 & 558 & 556 \\
\hline & 688 & 430 & 557 & 565 & 562 \\
\hline
\end{tabular}

The accuracy of the offline self-learning can be judged based on the deviation of three measurements of each gear position. From Figure IV and Table II, it can be seen that three static self-learning are all good, deviation of three measurements of each gear position is very small, and within the error scope permitted by the control system, which shows that the offline self-learning strategy developed for gear position has very high precision and robustness, and can take average value of three times as the actual gear position, then write it into TCU for the system to call. The time of whole selflearning process is very short, only $25 \mathrm{~s}$, which greatly improved the calibration efficiency of the AMT gear position.

B. Results and Analysis of Online self-Learning Test

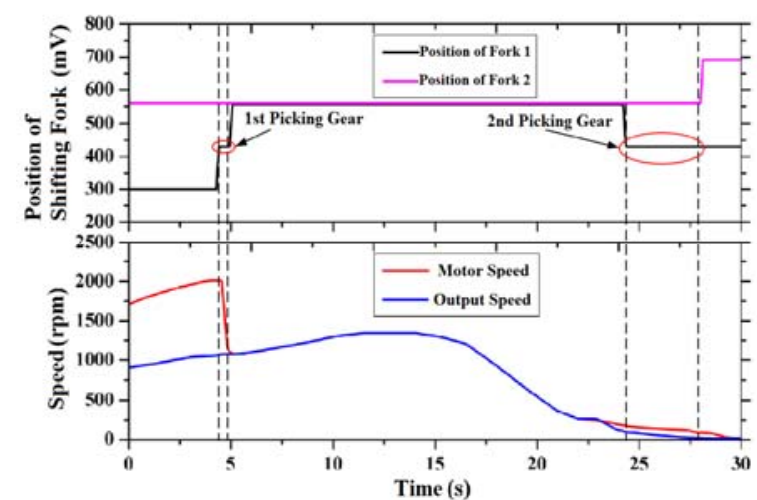

FIGURE V. SHIFTING PROCESS CURVE OF GEAR POSITION CHANGES IN THE VEHICLE RUNNING PROCESS

As shown in Figure V, there appeared the following situations in the process of vehicle running process: at the 
previous shift, the time for AMT system to pick neutral gear is just 0.127 (spacing between two dotted line), but when the next shift, the picking time is $3.23 \mathrm{~s}$, far higher than the normal time. We analyze motor speed and speed of AMT output shaft and find that there is no ratio relation between them, which means that it's the end of gear picking at this time. This is due to the change of neutral gear position parameters, and it's not in the value range, so the program has been judging that gear picking is not finished. This kind of situation will lead to the worse shifting quality, longer time of power interruption, lower running safety and riding comfort. Then it meets the online self-learning conditions, and start online self-learning.

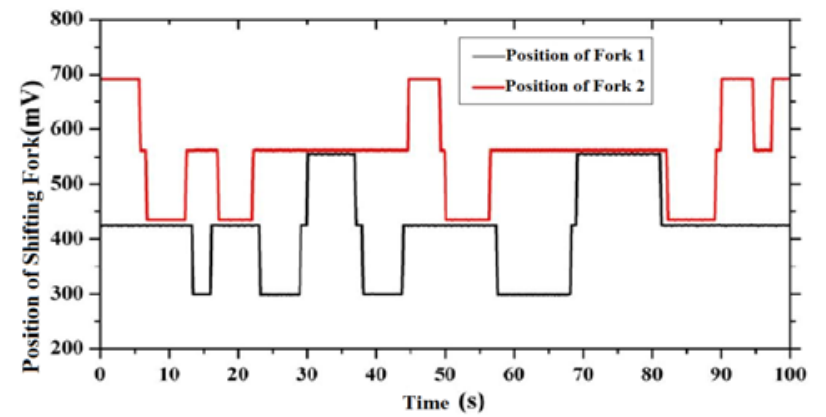

FIGURE VI. THE SHIFTING POSITION CURVE AFTER ONLINE SELFLEARNING OF GEAR POSITION

Figure VI shows the operation process after the completion of online self-learning. From the results, it can be seen that after self-learning on neutral gear position and update of the neutral target position, there is no longer binding phenomenon at the time of gear picking, AMT system can quickly and accurately get to the target gear position, which shows that the online self-learning strategy of gear position can effectively solve the binding shift caused by gear position changes in the vehicle running process, and has high precision.

Experimental verification of offline self-learning and online self-learning strategies for AMT gear position shows that the intelligent self-learning system of ATM gear position developed in this paper, can effectively judge the precise position of each AMT gear, which solved the problem of binding shift because of the change of gear position, and improved the shifting control accuracy and robustness of the actuator and the shifting success rate, thus achieved fast and accurate control of gear picking and gear shifting of AMT system.

\section{CONCLUSION}

In order to solve the problem of the decrease of control precision and binding shift because of the change of gear position of the AMT system, each ATM gear position is analyzed in detail in this paper, and the intelligent self-learning system including offline self-learning and online self-learning, for AMT gear position, is developed to accurately judge each AMT gear position, which ensures the shifting control accuracy and robustness of the actuator, and also improves the shifting quality of AMT system.

\section{ACKNOWLEDGMENT}

This work was supported by International S\&T Cooperation Program of China (Grant No. 2014DFA71790), the Key Scientific and Technological Project of Jilin Province (Grant No. 20160519008JH), Chinese National Natural Science Foundation (Grant No. 51575220) and Graduate Innovation Fund of Jilin University (Grant No. 2016170).

\section{REFERENCES}

[1] Y. Li, S. Chen, and Y. Wei, Research on Control Strategy of Selflearning for the AMT Shifting Actuator. [J]. Automotive Engineering, 2010, 10:878-882.

[2] L. Zhao, X. Mao, K. Zhu, H. Tang, and J. Wang, Control Technology Optimization of AMT Gear Self-learning in Commercial Hybrid Vehicles.[J]. Journal of Automotive Engineering, 2013, 01:9-14. 